\title{
The use of "LAST" operation in high risk patient
}

\section{L'uso dell'intervento “LAST" nei pazienti ad alto rischio}

\author{
Gennaro Ismeno, Antonio Falco, Francesco Paolo Tritto, Antonio d'Angelo, \\ Francesco Longobardi, Girolamo Damiani, Joseph Marmo, Rosario Gregorio, Luigi Piazza
}

\begin{abstract}
The use of "LAST" operation in high risk patient. G. Ismeno, A. Falco, F.P. Tritto, A. d'Angelo, F. Longobardi, G. Damiani, J. Marmo, R. Gregorio, L. Piazza.

Background: The LAST operation, in spite of few drawbacks, represents a good option for single Left Anterior Descending (LAD) revascularization. This procedure does not allow multivessel revascularization, where hybrid procedure have been previous described. We report preliminary experience with the LAST operation performed in high risk patients.

Matherial and Methods: From October 2004 to February 2005,11 male high risk patients (mean age $74 \pm 8$ years) underwent the LAST operation. Mean predicted death with EUROSCORE and Parsonnet score were $29 \%$ and $31 \%$ respectively. All patients had a proximal LAD lesion either not suitable for PTCA and multivessel coronary artery disease. The mean preoperative Ejection Fraction was 42 5 \% (27$55 \%)$. Four patients $(\mathbf{3 6 . 4 \%}$ ) had previous surgical myocar-
\end{abstract}

\begin{abstract}
dial revascularization. An incision of about $6 \mathrm{~cm}$ was made in the appropriate intercostal space and the LIMA (Left Internal Mammary Artery) was harvested using a special costal retractor. After heparin administration the LIMA is distally divided to check the adequacy of the blood flow. Following the insertion of a temporary intracoronary shunt, the LIMA was LAD anastomosis was carried out with a continuous 8-0 polypropylene suture.

Results: No hospital or late mortality was observed. Uneventful conversion to midline sternotomy was necessary in one patient with low value of mammary flow. All patients were discharged within the first postoperative week.

Conclusions: The use of the LAST operation enhances the role of minimally invasive surgery also in high risk patients who need coronary revascularization.
\end{abstract}

Monaldi Arch Chest Dis 2006; 66: 3-7.

Division of Cardiac Surgery, San Sebastiano Hospital, Via Tescione, 81100 Caserta, Italy.

Corresponding author: Dr Gennaro Ismeno; Via San Francesco ai Gerolomini, 2; 80078 Pozzuoli (NA); E-mail address: gennaroismeno@yahoo.com

Surgical revascularization of the Left Anterior Descending coronary artery (LAD) with the Left Internal Mammary Artery (LIMA) can be carried out through a left anterior small thoracotomy without cardiopulmonary bypass as a beating heart (LAST operation). This approach is quite appealing to the patients due to minimal invasiveness, short hospital stay and quick recovery.

The LAST operation, introduced and popularised by Calafiore et al. [1] can be considered nowadays a good option for patients with an isolated proximal LAD lesion not favourable for PTCA (total obstruction or type C lesion) or in care of recurrent stenosis following PTCA. However there are few drawbacks related to the LAST operation. First of all harvesting of the LIMA is technically demanding when is performed through a small anterior thoracotomy and the arterial conduit can be occasionally traumatised and/or irreversibly damaged. Furthermore, due to a difficult exposure, the branches of the upper portion of the LIMA are usually not divided and this might produce a steal phenomenon with recurrent angina in spite of a patent LIMA graft [2].

Finally, the LAST operation has to be occasionally converted into a midline sternotomy procedure because the LAD is not appropriately identified or exposed through a small thoracotomy as is running intramurally as is diffuses diseases and an endoarterectomy can be required.
In this study we report our preliminary experience with the use of LAST operation in high risk patients.

\section{Matherial and Metods}

\section{The patients}

From October 2005 to Fabruary 2005, 11 male high risk pts (mean age $74 \pm 8$ years) underwent the LAST operation. In four patients $(36.4 \%)$ previous procedure of surgical myocardial revascularization was performed. Preoperative risk factor are listed in table 1.

Table 1. - Patients data

\begin{tabular}{lc}
\hline Risk Factor & Number (\%) \\
\hline - Familiarity & $2(18)$ \\
- Smoker & $8(73)$ \\
- Diabetes & $5(45.5)$ \\
- Obesity & $5(45.5)$ \\
- Hypertension & $6(54)$ \\
- Dislipidemia & $10(91)$ \\
- FEV1<80\% & $7(63.6)$ \\
- Renal falure & $3(27)$ \\
- Carotid disease & $8(73)$ \\
- Redo procedure & $4(36)$ \\
\hline
\end{tabular}


All patients had high value of preoperative risk, mean predicted death with EUROSCORE and Parsonnet (figure 1) score were $29 \%$ and $31 \%$ respectively (table 1).

All patients had a proximal LAD lesion either not suitable for PTCA (9 patients) or previously submitted to unsuccessful PTCA (2 patients) and multivessel coronary artery disease. Angina pectoris was invariably present or predominant symptom in the preoperative course. Although 3 patients had a previous myocardial infarction involving part of the anterior ventricular wall and the septum, important ventricular dysfunction did not occur. (The mean preoperative Ejection Fraction in the study group was: $42.5 \pm 5 \%)$. Four patients $(36.4 \%)$ had previous surgical myocardial revascularization. Three patients had insulin-dependent diabetes mellitus. The quality of the LAD distal to the obstructing lesion however was considered acceptable at angiography, in all patients.

\section{The technique}

After induction of anesthesia the patient is intubated with a double-lumen endotracheal tube to allow exclusion of the left lung when necessary during the procedure. The central lines are inserted as usually and the right radial artery is cannulated for arterial pressure monitoring. External defibrillation pads are appropriately placed on the chest wall. The patients are placed in a supine position with the left hemithorax elevated approximately 30 degree and are draped so as to expose the entire chest and the groins.
Using the sternal angle as a guide to the second rib on the left side, the fourth rib is palpated. An incision is made directly over the fourth interspace wich is above the nipple. The pectoral muscle is divided and dissected from the bone as necessary to enter the fourth intercostals space. No cartilage or ribs are removed. The intercostals muscle is dissected off the cephalad portion of the $5^{\text {th }}$ rib (figure 2). Care is taken not to injure the mammary artery medially. Once all the muscle fibers are divided the mammary artery is identified in the fat. The lung is deflated or packed away. The CTS Lift (CTS) set is inserted and the upper chest elevated, the lower portion depressed. The mammary artery is dissected in the usual fashion. Branches are clipped. The artery must be taken as far as possible to the apex of the chest and the medial pleura and thymus must be divided to provide adequate length. The CTS Stabilizer set is inserted and the mammary can be dissected caudally for one additional interspace. Heparin is administered (50\% of the dose, ACT >280) and the mammary artery divided. The mammary artery is tailored for anastomosis and suspended from a towel or sponge draped over the cephalad portion of the incision. The pericardium is opened longitudinally over the LAD and a pericardial cradle created (figure 3). The retractor stabilizer is positioned to immobilize the artery and the heart. A $\mathrm{CO} 2$ blower is used to keep the anastomotic site free of blood. The LAD is dissected from the fat and controlled proximally with a compression and an intravascular shunt is inserted. The anastomosis is performed using a parachute coronary anastamotic technique. The mammary artery pedicle is sewn to the fat using 5-0

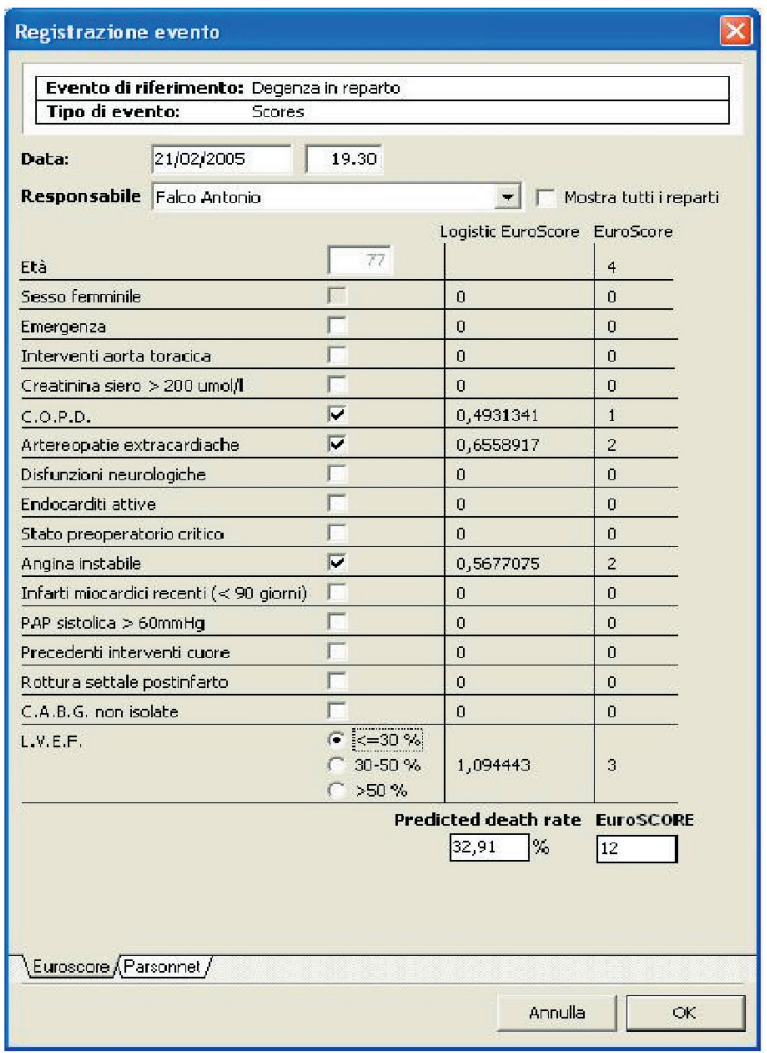

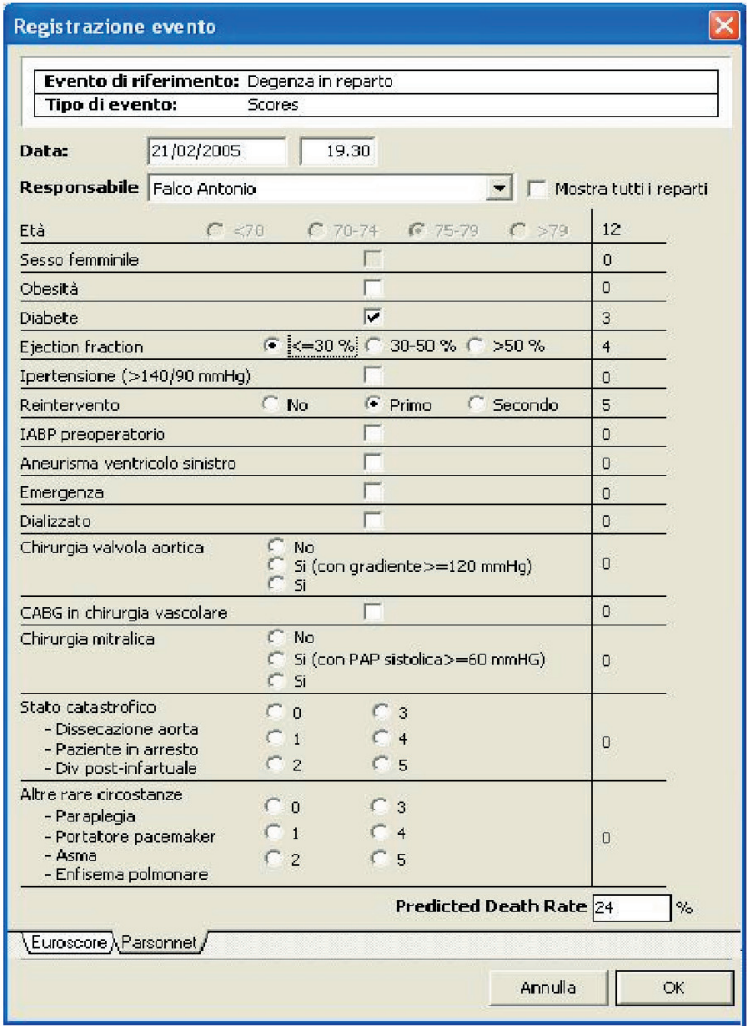

Figure 1. - Automatic evaluation of EUROSCORE and PARSONNET. 


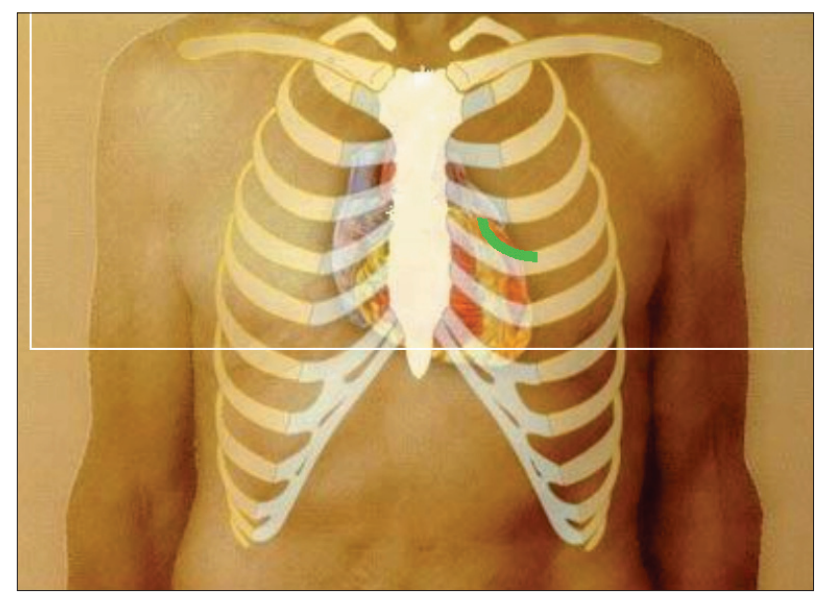

Figure 2. - Surgical access (Green Line) on Left wall of the chest.

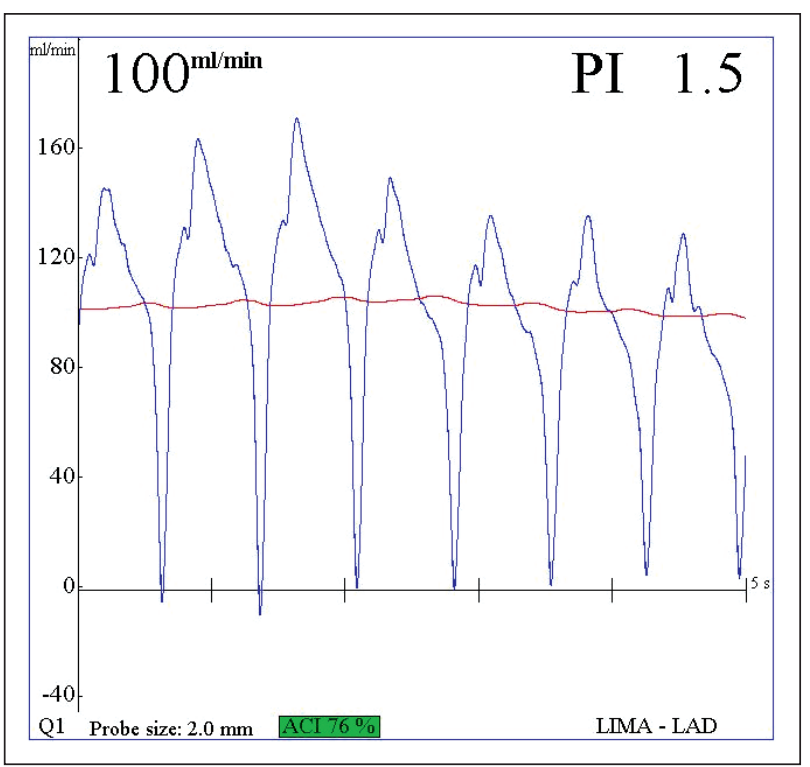

Figure 4. - Flow measurement with Medi-stim.

suture. A Medi-stim evaluation was performed in all cases (figure 4). The heparin is reversed with protamine. The ribs are reapproximated. The pectoral muscle, subcutaneous tissue and the skin are closed with adsorbable suture.

\section{Results}

No hospital or late mortality was observed in this cohort of high risk patients.

The length of the conduit (mammary artery) was always adequate in $100 \%$ of the cases.

The entire procedure was always completed within 4 hours. Conversion to midline sternotomy was necessary in one case to perform myocardial revascularization for low flow of the mammary artery harvested with minithoracotomy; an off-pump aorto-coronary by-pass on LAD was performed using saphenous vein. This patient had an uneventful postoperative course. In two cases LIMA-LAD anastomosis were repeated for bad value of Mean Flow (MF) and Pulsatily Index (PI) with the Medistim evaluation. The mean values of MF and PI were $27 \pm 4$ and $2.1 \pm 0.5$ respectivelly. No case of surgical revision for intraoperative bleeding was re-

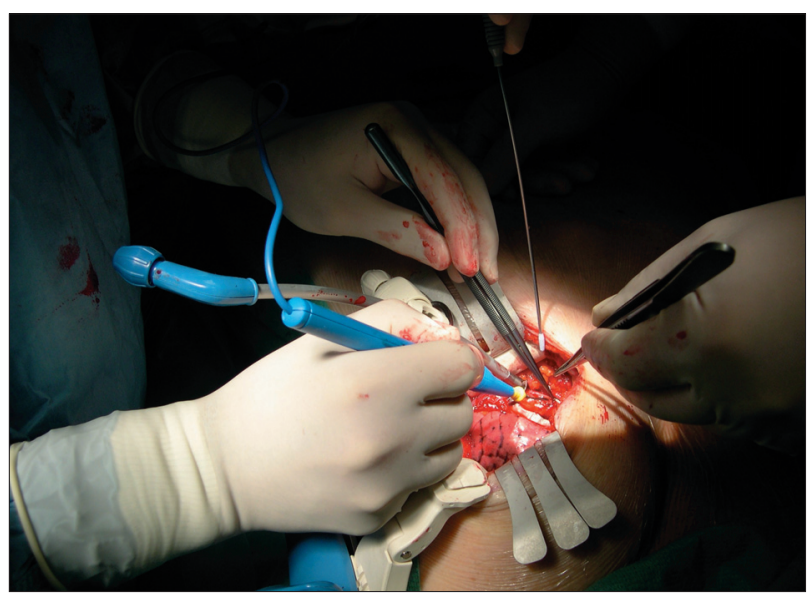

Figure 3. - LAST operation.

quired. In all patients the average postoperative bleeding was less than expected for a conventional operation $(310 \pm 50 \mathrm{ml})$. No patients required transfusion of blood or blood substitutes.

A case of left pneumothorax requiring chest drainage was recorded in the 3 th postoperative day.

No perioperative myocardial infarction or other major complications were observed and no abnormal enzyme level elevation was recorded.

Temporary atrial fibrillation, occurred in three cases $(27.3 \%)$ and was pharmacologically treated with success (i.v. amiodarone).

No cases hybrid procedure was performed although multivessels disease.

None perioperative embolic event was recorded. All patients were discharged within the first postoperative week and resumed normal day life activities within the second postoperative week.

All cases of Redo procedure (4/4) were discharged from the hospital without complications. Ventilation time, length of ICU stay and length of Hospital stay are reported in table 2 . All patients remained asymptomatic with medical therapy during the follow-up.

\begin{tabular}{lc} 
Table 2. - Results & \\
\hline & Mean (range) \\
\hline Ventilation time (hours) & $5(3-14)$ \\
ICU stay (hours) & $37(18-53)$ \\
Hospital stay (days) & $6.7(6-7)$ \\
\hline
\end{tabular}

\section{Discussion}

The "LAST" operation is a good option in patients $[5,6]$ with complete LAD obstruction or lesions which are defined not suitable for PTCA and those who have been already submitted to one or more PTCA procedures who have experienced recurrence of stenosis. The "LAST" operation undoubtedly represents a good option also in patients with previous myocardial revascularization without the use of mammary artery. Excellent results have 
been repeatedly reported by different groups $[1,7,8$, 9] and patency rate of the LIMA to LAD anastomosis above $95 \%$ has been documented [10].

Furthermore, the LAST operation offers the advantages associated with a minimally invasive approach, namely a short hospitalization time and a fast recovery. In our experience all patients were discharged within the first postoperative week.

Moreover off-pump approach without aortic manipulation showed minor incidence of embolic and bleeding complications (Calafiore). Many surgeons, however are reluctant to perform the LAST operation because of the difficult LIMA harvesting through the small thoracotomy. In addition the inappropriate divarication or exposure of the LAD, as well as the appreaciation of a diffuse diseased intramural vessel, may occasionally lead the surgeon to perform midline sternotomy following thoracotomy.

Introduction into the clinical practice of specialized instrumentation, for stabilzation during the anastomosis and the possibility to evaluate graft flow (Echo Doppler) immediately, allowed a wider spread of performing LIMA to LAD grafting through a LAST (Calafiore).

The reoparation for coronary artery disease through median sternotomy is a high risk procedure with high incidence of complications as right ventricule damage, bleeding, low cardiac output, renal and respiratory insufficiency, etc.

In our small series of four Redo procedure no cases of complications were recorded.

Moreover the advent of Drug-Eluting stents shoved better results and start the use of hybrid procedure (Murphy 2004). The hybrid myocardial revascularization remain attractive in situations such as redo procedures, in patients with significant morbidity, and in those with severe aortic or mitral ring calcification in whom moving or elevating the heart during revascularization of the posterior coronary vessels might result in injury of the calcified ascending aorta or the mitral annulus.

The quality of the LIMA graft and the blood flow through it can be evaluated before anastamosis tailoring. The length of the conduit was always adequate in $100 \%$ of cases of our group. In this series all patients had an LAD of acceptable quality and never running intramurally. Only one patient of this series $(9 \%)$ required midline sternotomy for inadequate flow of the mammary artery.

In this series optimal exposure of the operative field was uniformly obtained with minimal costal retraction. It is well recognized that excessive costal retraction results in postoperative chest pain and discomfort.

No cases of complications due to incomplete myocardial revascularization were recorded.

In conclusion, the use of the LAST operation enhances the role of minimally invasive surgery also in coronary artery revascularization in patients with high risk.

The minimally invasive approach, preferred for patients with low surgical risk in the past, can be used satisfactory in high risk patients or in Redo procedure. Further studies are necessary to perform a correct evaluation and long-term follow-up.

\section{Riassunto}

La LAST (Left Anterior Short Thoracotomy) operation, nonostante gli iniziali scetticismi, rappresenta una valida opzione per la rivascolarizzazione della LAD (Left Anterior Descending Artery). Questa procedura non consente la rivascolarizzazione completa nella patologia multivasale per cui approcci ibridi sono stati precedentemente descritti. Noi riportiamo l' esperienza preliminare con la LAST operation nei pazienti ad alto rischio.

Materiali e metodi: Da Ottobre 2004 a Febbraio 2005, 11 pazienti ad alto rischio (tutti di sesso ma-

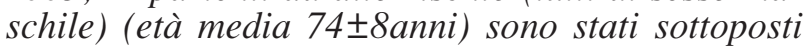
ad una LAST. Il rischio di mortalità operatorio predetto con EUROSCORE e Parsonnet è stato rispettivamente $29 \%$ e $31 \%$. Tutti i pazienti presentavano una lesione della LAD non trattabile con PTCA ed una patologia coronaria multivasale. La Frazione di Eiezione media preoperatoria era $42 \pm 5 \%$ (27$55 \%)$. Quattro pazienti (36.4\%) erano già stati sottoposti a rivascolarizzazione miocardia chirurgica. Una incisione di circa $6 \mathrm{~cm}$ viene fatta al IV o al V Spazio intercostale di sinistra e la LIMA (Left Internal Mammary Artery) viene esposta utilizzando uno speciale retrattore costale. Dopo eparinizzazione la mammaria (LIMA) viene distalmente preparata per l'anastomosi. Dopo l'introduzione di uno shunt intracoronarico temporaneo l'anastomosi fra LIMA e $L A D$ viene realizzata con una sutura continua di polipropilene 8-0.

Risultati: Nessun caso di decesso sia ospedaliero che a distanza è stato osservato. In un solo caso è stata necessaria la conversione a sternotomia per la presenza di scarso flusso della mammaria prelevata mediante la minitoracotomia. Tutti i pazienti sono stati dimessi entro la prima settimana postoperatoria.

Conclusioni: L' uso della LAST operation accresce il ruolo della chirurgia mininvasiva anche nei pazienti ad alto rischio.

\section{References}

1. Calafiore AM, Di Giammarco GD, Teodori G, et al. Left anterior descending coronary artery grafting via left anterior small thoracotomy without cardiopulmonary bypass. Ann Thorac Surg 1996; 61: 1658-65.

2. Schmid C, Heublein B, Reichelt S, Borst HG. Steal phenomenon caused by a parallel branch of the internal mammary artery. Ann Thorac Surg 1990; 50 (3): 301-6.

3. Mohr FW, Falk V, Diegeler A, Autschbach R. Computer enhanced coronary artery bypass surgery. $J$ Thorac Cardiovasc Surg 1999; 117: 1212-3.

4. Loulmet D, Carpentier A, d'Attellis N, Mill F, Rosa D, Guthart G, Berrebi A, Cardon C, Ponzio O, Aupecle B. First endoscopic coronary artery bypass grafting using computer assisted instruments. J Thorac Cardiovasc Surg 1999; 118: 4-10.

5. Bypass Angioplasty Revascularization Investigation (BARI) Investigators. Comparison of coronary bypass surgery with angioplasty in patients with multivessel disease. N Engl J Med 1996; 335: 217-225.

6. CABRI Trial Participants, Coronary Angioplasty vs. Bypass Revascularization Investigation (CABRI) results during the first year. Lancet 1995; 346: 1179-1183. 
7. Subramanian VA, McCabe JC, Geller CM. Minimally invasive direct coronary artery bypass grafting: two year clinical experience. Ann Thorac Surg 1997; 64: 1648-53.

8. Cremer JT, Wittwer T, Böning A, Anssar M, Kofidis T, Mügge A, Haverich A. Minimally invasive coronary artery revascularization on the beating heart. Ann Thorac Surg 2000; 69: 1787-91.

9. Benetti FJ, Bellester C, Sani G, Boonstra P, Grandjean J. Video assisted coronary artery bypass surgery. Ann Thorac Surg 1996; 61: 1658-65.

10. Calafiore AM, Di Giammarco G, Deodori G, Gallina S,
Maddestra N, Paloscia L, Scipioni G, Iovino T, Contini M, Vitella G. Midterm results after minimally invasive coronary surgery (LAST operation). J Thorac Cardiovasc Surg 1998; 115 (4): 763-771.

11. Boylan MJ, Lytle BW, Loop FD, et al. Surgical treatment of isolated left anterior descending coronary stenosis. Comparison of left internal mammary artery and venous autograph at 18 to 20 years of follow-up. J Thorac Cardiovasc Surg 1994; 107: 657-62.

12. Mack MJ, Magovern JA, Acuff TA, Landreneau RJ, Tennison DM, Tinnerman EJ, Asborne JA. Ann Thorac Surg 1999; 68: 383-90. 